\title{
Correction to: Gender differences in nerve regeneration after sciatic nerve injury and repair in healthy and in type 2 diabetic Goto-Kakizaki rats
}

Lena Stenberg $^{*}$ and Lars B. Dahlin

\section{Correction to: BMC Neurosci 15:107 (2014)}

https://doi.org/10.1186/1471-2202-15-107

Following the publication of the original article [1], the authors reported an error in the calculation of the total cell number at SNL and SND.

The values for the total cell number $\left(\mathrm{mm}^{2}\right) \mathrm{SNL}$ and total cell number $\left(\mathrm{mm}^{2}\right)$ SND in Table 1 (page 2) should be multiplied by 4.7 . This does not change anything about the other results or the drawn conclusion in the paper.

The amended version of Table 1 can be found below. 
Table 1 Nerve regeneration after nerve injury and repair in healthy and diabetic rats

\begin{tabular}{|c|c|c|c|c|c|c|c|}
\hline & Healthy & Healthy & Diabetes & Diabetes & $p$-values & Fisher's m & $d^{b}$ \\
\hline & $(n=10)$ & $(n=10)$ & $(n=10)$ & $(n=10)$ & & $\begin{array}{l}\text { Male/ } \\
\text { female }\end{array}$ & $\begin{array}{l}\text { Healthy/ } \\
\text { Diabetes }\end{array}$ \\
\hline $\begin{array}{l}\text { Axonal outgrowth } \\
\text { (neurofilaments, } \\
\text { mm) }\end{array}$ & $\begin{array}{l}7.0 \\
(6.8-7.3)\end{array}$ & $\begin{array}{l}6.3 \\
(6.1-6.4)\end{array}$ & $\begin{array}{l}6.9 \\
(6.7-7.1)\end{array}$ & $\begin{array}{l}5.8 \\
(5.1-6.2)\end{array}$ & 0.0001 & $<0.0001$ & 0.02 \\
\hline $\begin{array}{l}\text { ATF-3 } \\
\text { (\% of total) SNL }\end{array}$ & $\begin{array}{l}17.8 \\
(17.6-18.4)\end{array}$ & $\begin{array}{l}17.6 \\
(16.7-18.0)\end{array}$ & $\begin{array}{l}19.8 \\
(19.1-21.1)\end{array}$ & $\begin{array}{l}16.4 \\
(15.7-17.3)\end{array}$ & 0.0001 & 0.0001 & 0.001 \\
\hline $\begin{array}{l}\text { ATF-3 } \\
\text { (\% of total) SND }\end{array}$ & $\begin{array}{l}19.2 \\
(17.7-19.6)\end{array}$ & $\begin{array}{l}19.5 \\
(18.9-20.1)\end{array}$ & $\begin{array}{l}18.7 \\
(16.9-20.1)\end{array}$ & $\begin{array}{l}15.2 \\
(14.4-15.7)\end{array}$ & 0.0001 & 0.0003 & 0.001 \\
\hline $\begin{array}{c}\text { Cleaved caspase-3 } \\
\text { (\% of total) SNL }\end{array}$ & $\begin{array}{l}5.2 \\
(2.6-7.8)\end{array}$ & $\begin{array}{l}3.1 \\
(2.9-3.4)\end{array}$ & $\begin{array}{l}9.6 \\
(8.7-11.6)\end{array}$ & $\begin{array}{l}7.0 \\
(6.4-10.1)\end{array}$ & 0.0001 & 0.31 & $<0.0001$ \\
\hline $\begin{array}{c}\text { Cleaved caspase-3 } \\
\text { (\% of total) SND }\end{array}$ & $\begin{array}{l}2.7 \\
(2.2-4.0)\end{array}$ & $\begin{array}{l}2.5 \\
(2.4-2.7)\end{array}$ & $\begin{array}{l}6.4 \\
(4.5-7.1)\end{array}$ & $\begin{array}{l}5.8 \\
(4.3-6.1)\end{array}$ & 0.0001 & 0.39 & $<0.0001$ \\
\hline $\begin{array}{l}\text { Total cell number } \\
\left(\mathrm{mm}^{2}\right) \text { SNL }\end{array}$ & $\begin{array}{l}5344 \\
(5297-5367)\end{array}$ & $\begin{array}{l}4935 \\
(4827-5010)\end{array}$ & $\begin{array}{l}5043 \\
(4916-5184)\end{array}$ & $\begin{array}{l}5118 \\
(4977-5161)\end{array}$ & 0.0001 & 0.0005 & 0.0001 \\
\hline $\begin{array}{l}\text { Total cell number } \\
\left(\mathrm{mm}^{2}\right) \text { SND }\end{array}$ & $\begin{array}{l}5344 \\
(5273-5414)\end{array}$ & $\begin{array}{l}5226 \\
(5020-5391)\end{array}$ & $\begin{array}{l}4949 \\
(4789-5128)\end{array}$ & $\begin{array}{l}5137 \\
(4911-5179)\end{array}$ & 0.0001 & 0.07 & $<0.0001$ \\
\hline $\begin{array}{l}\text { Preoperative } \\
\text { B-glucose } \\
\text { (mmol/l) }\end{array}$ & $\begin{array}{l}4.6 \\
(4.3-4.9)\end{array}$ & $\begin{array}{l}3.90 \\
(3.8-4.3)\end{array}$ & $\begin{array}{l}15.0 \\
(13.3-17.2)\end{array}$ & $\begin{array}{l}10.3 \\
(9.7-11.7)\end{array}$ & 0.0001 & $<0.0001$ & $<0.0001$ \\
\hline $\begin{array}{l}\text { Weight increase } \\
(\%)\end{array}$ & $\begin{array}{l}2.2 \\
(0.7-2.7)\end{array}$ & $\begin{array}{l}2.4 \\
(1.3-4.8)\end{array}$ & $\begin{array}{l}2.0 \\
(1.2-2.6)\end{array}$ & $\begin{array}{l}2.6 \\
(2.0-3.2)\end{array}$ & 0.34 & - & - \\
\hline
\end{tabular}

Values are median 25th (Q1)-75th (Q3) percentiles. p-values in italics is significantly different at least at the 0.05 level. ${ }^{\mathrm{a}} \mathrm{KW}=\mathrm{Kruskal}-\mathrm{Wallis} .{ }^{\mathrm{b}} \mathrm{Fisher}$ method for independent samples based on the chi square distribution. SNL site of lesion, SND distal nerve segment. Total cell = DAPI stained cells

Published online: 03 November 2020

\section{Reference}

1. Stenberg L, Dahlin LB. Gender differences in nerve regeneration after sciatic nerve injury and repair in healthy and in type 2 diabetic Goto-Kakizaki rats. BMC Neurosci. 2014;15:107. https://doi. org/10.1186/1471-2202-15-107.

\section{Publisher's Note}

Springer Nature remains neutral with regard to jurisdictional claims in published maps and institutional affiliations. 